As we move into the next millennium, where in the world can we find the "world's best practice" in tobacco control? Where are the benchmarks that tobacco control advocates can cite as examples of what is possible? For this issue, which will be distributed to all delegates at what promises to be the largest tobacco control meeting ever held-the 11th World Conference on Tobacco or Health, in Chicago, 6-11 August 2000 - we have asked 10 contributors to outline cases for particular nations to be considered. - ED

\title{
World's best practice in tobacco control
}

\section{Most comprehensive tobacco control programme: New Zealand}

Several American state programmes have seen adult smoking prevalence levels fall below $20 \%$. The Singaporean programme maintains a low smoking prevalence among women. Sweden has the lowest tobacco consumption per adult among industrialised OECD countries, but the most rapid decrease in consumption has been in New Zealand, ${ }^{1}$ where consumption has halved in 15 years and adult prevalence has reduced by one quarter, from $32 \%$ in 1981 to $24 \%$ in 1996 (census data, see table 1).

Most New Zealand doctors had quit smoking before the Tobacco Institute (1980), ASH (Action on Smoking and Health) (1982), and the Department of Health (1984) employed staff to work on the tobacco issue. Between 1980 and 1994 the government tripled revenue from tobacco tax and halved tobacco consumption per adult. The government increased tobacco tax rates most years up to 1991, and again in 1995 and 1998. Costliness doubled, from 11 minutes to earn 20 cigarettes at average wage rates in 1981, to 22 minutes in 1994 to 23 minutes in 1998. Smokers are now extremely price responsive; the 1998 tax increase raised prices $13 \%$, and shop sales fell $10 \%$ within a week, a result confirmed by the decrease in releases for sale between 1997 and 1999.

Health Minister (now Prime Minister) Helen Clark's Smoke free Environments Act in 1990 banned tobacco advertising, restricted smoking in workplaces, and replaced tobacco sports sponsorships with health sponsorships. A coalition of 250 voluntary agencies supported the government. In 1996 over $90 \%$ of smokers said they had quit for more than one day. Despite these quitting attempts, adult prevalence measured 1996-99 on doorstep surveys remained at $26 \%$. A quit campaign was added in mid-1999. In 2000 the government was expected to raise tobacco tax further, and to legislate for smoke free workplaces, schools and grounds, restaurants and eventually stand alone bars (table 1).

The task is incomplete. A truly comprehensive programme needs to regulate the cigarette itself. In line with the recommendations of a recent WHO conference ${ }^{2}$ regulation would involve brand licensing requiring manufacturers to fully disclose their processes, recipes and additives, to avoid high nicotine content tobacco, ${ }^{34}$ sweeteners, or ammonia boosting, and to reduce toxicity. Within 5-10 years we expect to see "tax to the max" policies implemented which could halve consumption again. Taxation and regulation together could also enable remaining smokers to switch to less harmful products: either Eclipse-type tobacco-warmed addictive aerosol "cigarettes"; non-nicotine cigarettes; or cigarette look-alike nicotine aerosols.

Public Health Physician,

MURRAY LAUGESEN

Health New Zealand,

laugesen@healthnz.co.nz

1 Laugesen M, Swinburn B. New Zealand's tobacco control programme 1985-1998. Tobacco Control 2000;9:155-162.

Table 1 Components of the comprehensive programme, New Zealand, March 2000

\begin{tabular}{|c|c|}
\hline Programme variable & Status \\
\hline Cigarette smoking prevalence age 15 and over & $\begin{array}{l}21 \% \text { in } 1996 \text { telephone survey, } 24 \% \text { in } 1996 \text { census, doorstep survey } \\
\quad 1996,26 \% ; 1999,26 \%\end{array}$ \\
\hline Cigarettes per smoker age 15 and over & 16 per day in 1996,15 in $1997-98,14$ in 1999 \\
\hline Tobacco consumption per adult age 15 and over & $\begin{array}{l}\text { Average annual compound decrease: } 1981-90,4.2 \% ; 1990-99,4.5 \% \text {; } \\
1999 \text { level circa } 1300 \text { cigarettes pa }\end{array}$ \\
\hline Tobacco tax and price (increases ongoing) & $\begin{array}{l}23 \text { minutes at average wage rates needed to earn } 20 \text { cigarettes. Tax } \\
\text { rate uniform per gram of tobacco, and inflation adjusted since } 1990\end{array}$ \\
\hline Tobacco advertising (bans took effect in 1990-98) & $\begin{array}{l}\text { Advertising only in imported magazines; no tobacco sponsorships or } \\
\text { shop advertising permitted }\end{array}$ \\
\hline Smoking restrictions (from 1991) & $\begin{array}{l}\text { Not permitted in offices, shops, or most public transport. Restricted in } \\
\text { restaurants. }\end{array}$ \\
\hline Quit campaign (1999) & $\begin{array}{l}\text { Media campaign supported by a free telephone help line, its number } \\
\text { printed on each cigarette packet }\end{array}$ \\
\hline Sales restrictions & $\begin{array}{l}\text { Oral tobacco sales not permitted. For smoking products, minimum age } \\
\text { of purchaser is } 18 \text { years }\end{array}$ \\
\hline Tobacco packet labelling $(1988,2000)$ & $\begin{array}{l}\text { Warnings were varied and strong from 1988. From 2000, "Smoking } \\
\text { kills" was printed both in English and Maori }\end{array}$ \\
\hline Products and additives & Controls on content not yet in place \\
\hline
\end{tabular}


2 World Health Organization. International conference on advancing knowledge on regulating tobacco products, draft recommendations, Oslo. Geneva: World Health Organization, 2000. In press

3 Blakely T, Laugesen M, Symons R, Fellows K. New Zealand cigarettes have a high nicotine content. NZ Public Health Rep 1997;4:33-4

4 Blakely T, Symons R. Update on nicotine concentration in New Zealand-manufactured cigarettes. NZ Public Health Rep 1997;4:85.

\section{Tobacco taxation}

As with virtually all other products, demand for tobacco products falls as prices rise. The strength of this relation has been shown to vary between nations and demographic groups. ${ }^{5}$ But from a public health standpoint there is no doubt that, other things being constant, tobacco product price increases will reduce overall tobacco consumption. ${ }^{6}$ There is also strong evidence that the impact of price increases is particularly strong among young people, ${ }^{7}$ making tax policy one of the main tools in reducing the onset of tobacco dependency, ${ }^{8}$

Tax policy has a significant impact on the overall market for tobacco. The affordability of tobacco products is influenced by a combination of prices and incomes. Tax levels influence prices and tax levels can be influenced by public health arguments. Advocacy on tobacco taxation can therefore change the overall affordability equation and reduce aggregate demand for tobacco products.

Tobacco tax policy can also have a significant impact on the types of tobacco products used. Many countries, for instance, have lower taxes on roll-your-own tobacco. Others, by basing the tax structure on a percentage of the wholesale price, will accentuate the advantage given to less expensive cigarettes.

Tax increases without other measures to help smokers to quit are less effective from a health standpoint. Both anticipated and actual cigarette price increases encourage people to attempt to stop smoking or to reduce their smoking, ${ }^{8 a}$ but increasing the availability of tobacco dependence treatment products and services increases the numbers of people who will be successful.

Good tobacco tax policy will seek to:

(1) Significantly raise the price of tobacco products, as has occurred most notably in countries such as the UK where a packet of 20 cigarettes cost around \$US6.30 in December 1999.

- To maximise impact, experience suggests that each tax increase should increase consumer prices by at least $20 \%$.

- Further increases should follow.

- The government should clearly state its intention to raise tobacco taxes considerably over time, enabling consumers to prepare for future price increases by not starting or quitting.

(2) Ensure that tax levels are not eroded by inflation. In some countries-for example, in Australia and New Zealand - tax rates are increased regularly in line with increases in consumer prices. Preferably however, tobacco tax rates should be subject to increases frequent and large enough to compensate for increases in disposable income.

- There should be a policy of raising the tax by at least 3-5\% per year more than the rate of inflation.

- In countries with rapid economic growth the increases will need to be greater to compensate for increases in disposable income.

(3) Prevent loopholes that would allow switching to cheaper tobacco products.

- The specific tax applied to all tobacco products should be high enough to ensure that there are no "entry level" cheap cigarettes available.

- The taxes applied to roll-your-own tobacco products, smokeless tobacco, etc, must be, in the absence of a health justification for different treatment, equal to that of an equivalent quantity of manufactured cigarettes. This has been attempted, for instance, in Australia and New Zealand, where rollyour-own tobacco is taxed at a rate equivalent to that applied to standard cigarettes

(4) Link the tobacco tax policies to overall tobacco control policies, so as to show the health basis to the tax.

- As has happened on occasion, such as in Victoria (Australia) and California, in the late 1980s, in Massachusetts in the early 90 s, and most recently in the UK, and Ireland, governments should simultaneously announce action on other areas of tobacco control, reinforcing the health message of the tax increase and making it harder to characterise as simply a cynical "tax grab".

- In particular, they should set in place measures to increase people's access to effective tobacco dependence treatment products and services.

(5) Take measures that will prevent the smuggling of tobacco products.

- Require sophisticated covert and overt tax markings on all tobacco products.

- Ensure that product markings allow detailed tracing of any products (including exports) through the distribution chain.

- Increase and enforce penalties for smuggling. Smuggling must be seen as a clear loss making business in order to discourage it.

- Hold tobacco companies and their executives liable for any involvement in activities that contribute to smuggling.

$$
\text { MICHELLE SCOLLO }
$$

VicHealth Centre for Tobacco Control,

Carlton South,

Victoria, Australia;

mscollo@bigpond.net.au

DAVID SWEANOR

Non-Smokers Rights Association of Canada,

Ottawa, Canada,

dsweanor@nsra-adnf.ca 
The authors of this contribution declined to nominate the "world's best" tobacco taxing nation, arguing that: there is no consensus about a minimum desirable level of proportional taxes; no country is increasing taxes, regularly, in line with increases in disposable income; and no country is investing sufficiently in price revenue protection. While the UK currently has the highest tax rates, smuggled products are widely available, making licit tobacco prices pretty much irrelevant.-ED

5 World Bank, Curbing the epidemic: governments and the economics of tobacco control. Washington DC: The World economics of

6 US Department of Health and Human Services. Reducing the health consequences of smoking: 25 years of progress. A
report of the Surgeon General, 1989. Rockville, Maryland: report of the Surgeon General, 1989. Rockville, Maryland:
Public Health Service, Centers for Disease Control, Office Public Health Service, Centers for Disease Control, Office
on Smoking and Health, 1989. (DHHS Publication No on Smoking and He

7 Centers for Disease Control and Prevention. Response to increases in cigarette prices by race/ethnicity, income and age groups-US, 1976 -1993. MMWR Morbid Mortal Wkly Rep 1998;47

8 US Department of Health and Human Services. Preventing tobacco use among young people. A report of the Surgeon General, 1994. Atlanta, Georgia: Public Health Service, Centers for Disease Control and Prevention, Office on Smoking and Health, 1994. (US Government Printing Office Publication No S/N 017-001-00491-0.)

8a Chaloupka FK. Rational addictive behaviour and cigarette smoking. Fournal of Political Economy 1991;99:722-42.

Increasing quitting by increasing access to treatment medications: USA

Along with efforts to prevent smoking in youth, it is essential to accelerate quitting among current smokers by increasing the number of smokers who attempt to quit, and by increasing the success of those attempts.

Cessation can be promoted by making effective treatment more available and visible. Treatment increases success in quitting, and the wide availability and promotion of treatment can promote increased quit attempts. Nicotine replacement therapy (NRT) - temporary provision of nicotine, in patches, gums, etc.-is a proven, effective aid for quitting smoking. ${ }^{9}$ Yet, access to NRT is often restricted by regulation, such as requiring prescriptions, limiting retail availability to pharmacies, and restricting the ability to advertise the medications. These barriers reflect an illogical regulatory framework in which cigarettes, which addict their users and cause unimaginable harm, are largely unregulated and granted nearly unrestricted access, while NRT, which is proven safe (other constituents in tobacco smoke are responsible for the harms of smoking) and effective in helping people quit, is fenced in by restrictions, warnings, and barriers. ${ }^{10}$

Experience in several countries has demonstrated the positive impact of making NRT more accessible. In the USA, use of NRT increased $150 \%$ in the year after nicotine patches and gum were switched from prescription only status to general sales (including sale in groceries, dry goods stores, etc), and in the four years thereafter. Even if all NRT use were limited to people who would have tried to quit anyway, the increased NRT use would result in at least 114000 additional quits annually in the USA. ${ }^{11}$

The liberalisation of NRT sales also is likely to prompt quit attempts. Introducing NRT into the US consumer product marketplace massively increased advertising for smoking cessation. In the year after NRT was switched to general sale, approximately US $\$ 100$ million was spent advertising NRT, resulting in high visibility and awareness of smoking cessation that almost certainly attracted additional smokers into quitting, and into treatment. If even half the NRT assisted quit efforts are new efforts, NRT produced at least 209000 new quits per year in the US.

The impact of advertising on NRT use was also illustrated in Australia, where a change in regulations simply allowed wider advertisement of NRT. NRT use doubled. ${ }^{12}$ Recent liberalisations of NRT marketing in France and Brazil appear to be yielding similar results. This trend hopefully reflects a shift away from the counterproductive regulatory position that still exists in too many jurisdictions. (In Japan, for example, the government has an interest in tobacco sales, and NRT is restricted to prescriptions for smokers who are already have smoking related disease).

While maintaining reasonable safeguards of safety and efficacy, regulation of NRT must be geared towards promoting treatment. Cigarettes are the most expertly and intensively marketed consumer products. Engaging consumer healthcare product companies in marketing smoking cessation may be the best way to beat the tobacco industry at its own game. Regulations should discourage smoking and encourage cessation and access to treatment.

University of Pittsburgh,

SAUL SHIFFMAN

Pinney Association

Pinney Associates,

JOE GITCHELL

201 North Craig Street,

Suite 320,

Pittsburgh, PA 15213, USA;

shiffman@pinneyassociates.com

9 Fiore MC, Bailey WC, Cohen SJ, et al. Smoking cessation Clinical Practice Guideline No 18. Rockville, Maryland: US Department of Health and Human Services, Public Health Service, Agency for Health Care Policy and Research, April 1996. (AHCPR Publication No 960692.); <http://text.nlm.nih.gov>.

10 Henningfield JE, Slade JD. Tobacco-dependence medications: public health and regulatory issues. Food Drug Law $\mathcal{F}$ 1998; 53(suppl):77-114.

11 Shiffman S, Gitchell JG, Pinney JM, et al. Public health benefit of over-the-counter nicotine medications. Tobacco Control 1997;6:306-10.

12 Chapman S, Borland R. Advertising of nicotine replacement therapy: has it promoted more smoking cessation? Parsippany, New Jersey: SmithKline Beecham Consumer Healthcare; 1999.

Dr Shiffman and Mr Gitchell, both of Pinney Associates, provide consultation on smoking control to SmithKline Beecham Consumer Healthcare.

Tobacco advertising and display of tobacco products at point of sale:

\section{Tasmania, Australia}

Tobacco control has long recognised the importance of reducing or eliminating any advertising of tobacco products. The governments of Singapore, New Zealand, and the Australian states and territories governments in ACT, NSW, and Tasmania have also taken steps to reduce tobacco advertising at point of sale.

In 1996, when the Tasmanian government began considering banning advertising at point of sale, tobacco control advocates warned that legislation that was insufficiently comprehensive, did not control or prohibit the display of 
tobacco products, and would cause the industry to respond with various display techniques that would overcome these restrictions.

Unless packets and carton displays are controlled (or preferably prohibited altogether as proposed for later in 2000 in New Zealand), cigarette packets can be used to make pyramids, mechanical windmills, entire walls of display stock, designs and patterns on walls, ceilings, floors, and anything else a creative advertising agency can dream up.

The recent history of point of sale legislation has provided many lessons for Australian states, with each state learning from the legal drafting flaws of predecessors. The state next to legislate is warned of any weakness and rarely makes the same mistake. Here are some fundamentals that should be incorporated into legislative drafts.

- Prohibit any advertisements of any kind everywhere, including at point of sale.

- Prohibit advertising of price discounting (no "was/is" signs) - for example, no crossed out prices with the new price underneath. Price discounting is attractive to children and teenagers who are price sensitive.

- Ensure that the prohibition covers all potential and actual gimcracks, baubles, and gimmicks. Ensure it precludes flags, banners, clothing, mobiles, wall hangings, carpets, coin mats, clocks, watches, child high fake packets, internally lit revolving cabinets and objects in associated colours and themes, and also colour coding.

- Prohibit lighting directed at product displays.

- Prohibit value added marketing devices, such as give aways with products-for example, cigarette lighters, calendars, books, maps, diaries, CDS, toys or cosmetics. These are particularly attractive to children.

- Prohibit display in association with or nearby products marketed for children (such as toys, videos, candy, sweets, crisps).

- Prohibit toys or confectionery that resemble tobacco or cigarettes.

- Prohibit audible as well as visual advertising.

- If at all possible, prevent misleading statements anywhere such as "light" or "mild".

- If at all possible, prohibit the industry from making false or misleading statements to retailers about display legislation. This particular provision in the Tasmanian legislation has proved invaluable in preventing tobacco representatives from telling retailers that a particular display is lawful, when it is not. The provision has substantially enhanced the efficacy of enforcement mechanisms.

It is important to never make the legislation dependent on subordinate legislation such as a regulation or guideline. Instead, put as much detail as possible into the primary legislation. Otherwise, this allows the tobacco industry to delay the implementation of legislation sometimes for years, while the consultation processes take place on the subordinate legisla- tion, and makes the legislation itself vulnerable to lobbying.

Ensure that legislation is easily enforced. Consult with enforcement officers during the drafting process and ask if they can envisage any difficulties. Anything that is difficult to enforce almost certainly will not be observed.

PASSING THE "SCREAM TEST"

Point-of-sale provisions that the tobacco industry hate include:

- large health warnings with no government attribution;

- spatial limits on the size of stock displays;

- small numerical limits on packs on display;

- bans on display of cartons or shippers;

- bans on display of larger packs;

- prohibition on advertising or display of products on vending machines (that is, brand names only).

WHAT TOBACCO COMPANIES LIKE, SUPPORT, AND PROPOSE

- Anything complex and hard to enforce.

- Anything difficult to prove-for example, that the person charged "knew" about the offence. This means that only an individual sales person gets caught and charged, not the store owner, with sales clerks having heavy job turnover rates.

There are other useful pieces of legislation that should be tied or linked to the primary tobacco legislation. Licensing of tobacco product sellers has three main advantages:

- it allows tobacco control officers to find the seller-for example, for enforcement purposes or to provide retailer education;

- it ensures that licenses can be cancelled if a retailer does not comply with display or other tobacco legislation;

- revenue from the licensing process can be used to employ enforcement officers and provide retailer information.

Infringement notices (on-the-spot fines, which can be issued by enforcement officers) improves compliance rates, allows swift and sure "punishment" for breaches of display provisions, without the complexity and cost of launching prosecution action, and has an immediate "educative" effect on the retailers concerned.

Notices in shops regarding the legislation should be very large and should include health warnings (both graphic and written), as well as information about who to contact in government about breaches and access to cessation programmes.

Nominated officers in Tasmania are volunteers (usually doctors, nurses, teachers, and other health workers, including antitobacco staff) appointed and trained by the department to undertake enforcement and education work, and empowered by legislation to issue on-the-spot fines. Such an enforcement regimen significantly enhances community involvement in tobacco control activities, and reduces reliance on governments. 
The tobacco industry will mount a number of counter arguments to prevent point-of-sale restrictions. These may or may not include:

- tobacco is a legal product;

- customers have a right to see the entire range of products;

- advertising has no effect on aggregate sales;

- display of product has no effect on sales;

- children are not interested in nor affected by tobacco products or displays.

All of these arguments are refutable, or can be dismissed, using logic and available research.

KATHY BARNSLEY

Public and Environmental Health Service, Tasmania

kathy.barnsley@dchs.tas.gov.au

Public Health, Tasmania

MARK JACOBS

Surveillance of patterns and consequences of tobacco use: USA

Surveillance of tobacco use can guide policy decisions, research initiatives, and the development and evaluation of intervention programmes. An ideal surveillance system would monitor variables contained in the traditional epidemiologic model of agent (that is, various tobacco products), host (that is, smoker/user or potential smoker/user), vector (that is, tobacco product manufacturers), and environment (economic, cultural, political, and historical), with attention also given to the incidental host (that is, involuntary smoker). ${ }^{13}$ Although no country measures all of these components in an optimal fashion, the surveillance system in the USA is extensive. Some of the key components are noted below.

AGENT

Agent factors, such as toxic constituents, $\mathrm{pH}$, and additives, are monitored at the Centers for Disease Control and Prevention (CDC), as well as by individual researchers and the Commonwealth of Massachusetts. Consumption data on various products are provided by the US Department of Agriculture. ${ }^{14}$ Information on the types of cigarettes consumed are provided by the Federal Trade Commission. ${ }^{15}$

HOST

Most surveillance work monitors host factors. In the USA, several population-based surveys at the national level measure tobacco use among young people. These include the Monitoring the Future (MTF) surveys ${ }^{16}$; the Youth Risk Behavior Survey (YRBS) ${ }^{17}$; the National Household Survey on Drug Abuse $(\text { NHSDA })^{18}$; and the National Youth Tobacco Survey (NYTS). ${ }^{19}$ The NYTS is dedicated totally to measuring tobacco related knowledge, attitudes, and behaviours. The MTF includes a longitudinal component. The National Health and Nutrition Examination Survey (NHANES) ${ }^{20}$ measures tobacco use and serum cotinine concentrations in children and adults, permitting biochemical validation of self reported tobacco use and exposure to environmental tobacco smoke. NHSDA data are collected at the state level. Most states conduct their own versions of the YRBS and the Youth Tobacco Survey.
Adult (ages 18 years and older) surveys that provide national estimates include the National Health Interview Survey, ${ }^{21}$ NHANES, and NHSDA. The Behavioral Risk Factor Surveillance System ${ }^{22}$ and the Current Population Surveys $^{23}$ provide national and state specific estimates.

The measures of tobacco use in each of these surveys are used to plot trends in prevalence across sociodemographic groups. Because each survey has a unique purpose, a large number of additional variables are available for analyses. Variables of interest include susceptibility to tobacco use, patterns of initiation, indicators of dependence, quitting patterns and methods, receipt of advice to quit from physicians and dentists, mental health indicators, use of alcohol and other drugs, numerous other risk behaviours, sources of tobacco, prices paid for cigarettes, usual brand, receptivity to marketing, awareness of tobacco control programmes, and opinions about tobacco control policies.

VECTOR

Several researchers study the vector-for example, by chronicling tobacco industry public relations, lobbying, and marketing activities in numerous states. National data on industry advertising and promotion expenditures are available from the FTC. ${ }^{15}$

ENVIRONMENT

Environmental surveillance includes state and local tobacco control legislation and programmatic activities ${ }^{24-26}$; exposure to health messages; and tobacco promotions, prices, and placement. ${ }^{25}$ The ASSIST media tracking system will provide a measure that can assess the print media's agenda as related to tobacco control. $^{26}$

HEALTH AND ECONOMIC CONSEQUENCES

The National Vital Statistics System coordinates data from state operated registration systems on births and deaths. ${ }^{27}$ Most states collect information about cigarette smoking on the birth certificate and some states ask, on the death certificate, if smoking contributed to the death. Morbidity data are available from cancer registries ${ }^{28}$ and from surveys of hospital discharges ${ }^{30}$ and medical expenditures. ${ }^{31}$

REPORTS

Reports of findings can often be found at each system's web site. CDC supports a data warehouse, the State Tobacco Activities Tracking and Evaluation system. ${ }^{24}$ Results of analyses of data are also reported in CDC's Morbidity and Mortality Weekly Report, reports of the surgeon general, National Cancer Institute Monographs, and in journal articles.

AREAS FOR GROWTH

Product surveillance could be expanded, especially if the companies were required to report brand specific constituent and additive content. Brand specific marketing data and expanded environmental monitoring would also permit important analyses. The 
population based surveys are generally released from seven months to two years after data collection is completed. In addition, questionnaire content is fairly rigid. Therefore, we would be more effective at detecting and responding to new trends with smaller, but more frequent (for example, bi-weekly or monthly) assessments of the population to assess reactions to new products and campaigns. Occasional (approximately every five years) longitudinal surveys of the natural histories of initiation and quitting would increase our understanding of these dynamic processes.

GARY A GIOVINO

Senior Research Scientist,

Roswell Park Cancer Institute,

Buffalo, New York, USA;

Gary.Giovino@RoswellPark.org

The writing of this report was supported by Project ImpacTeen, funded by the Robert Wood Johnson Foundation, through the University of Illinois at Chicago (Frank Chaloupka, Principal Investigator).

13 Orleans CT, Slade J. Preface. In: Orleans CT, Slade J, eds Nicotine addiction: principles and management. New York: Oxford University Press, 1993, ix-xi.

14 http://wwwecon ag gov/briefing/tobacco

15 http://www.ftc.gov

$15 \mathrm{http://www.ftc.gov}$

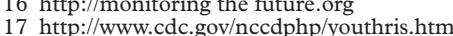

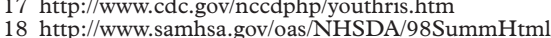

TOC.htm

$19 \mathrm{http} / / /$ www.cdc.gov/tobacco/nyts2000.htm

20 http://www.cdc.gov/nchs/nhanes.htm

$21 \mathrm{http}: / /$ www.cdc.gov/nchs/nhis.htm

22 http://www.cdc.gov/nccdphp/brfs

23 Gerlach KK, Shopland DR, Hartman AM, Gibson JT, Pechacek TF. Workplace smoking policies in the United States: results from a national survey of more than 100,000 workers. Tobacco Control 1997;6:199-206.

$24 \mathrm{http}: / /$ www2.cdc.gov/nccdphp/osh/state/index.htm

25 http://www.uic.edu/orgs/impacteen

26 Stillman F, Hartman A, Graubard B, et al. The American stop smoking intervention study: conceptual framework and evaluation design. Evaluation Review 1999;23:259-80 $27 \mathrm{http}: / /$ www.cdc.gov/nchs/nvss.htm

$28 \mathrm{http} / / / \mathrm{www} . \mathrm{cdc}$.gov/nchs/nvss.htm

$29 \mathrm{http}: / /$ www.cdc.gov/nccdphp/survcanc.htm

29 http://www.

31 http://www.meps.ahrq.gov

Smoke free public spaces: California

Most traditional tobacco control efforts have been directed at smokers (for example, smoking cessation, tax increases) or the tobacco industry (for example, advertising restrictions). The difficulty with these approaches is that the smokers are already addicted to nicotine and have accepted, to some degree, the rationalisations that tobacco advertising offers them, and that the tobacco industry is well practised at thwarting regulation. The California Tobacco Control Program, while including some traditional elements, took a different approach. They concentrated on the non-smokers.

The California campaign of the early 1990's - when it was effective-concentrated on educating non-smokers about the dangers of secondhand smoke and discrediting the tobacco industry. ${ }^{32}$ During this period, tobacco consumption fell precipitously, ${ }^{33}$ faster than anywhere else in the world.

The non-smokers, after all, are not addicted to nicotine and have not accepted the tobacco industry as part of their personal life. More important, non-smokers constitute the majority. Non-smokers object to breathing secondhand smoke. The problem has been that often the non-smokers and their political lead- ers are not aware of this strong social consensus. This fact, combined with aggressive actions by the tobacco industry to dispute the scientific evidence that involuntary smoking causes disease in non-smokers ${ }^{34}$ and to claim that clean indoor air laws cause economic chaos, ${ }^{35}$ has slowed the spread of clean indoor air laws, policies, and regulations.

Most progress on clean indoor air laws in the USA and North America has been made at the local level, where the tobacco industry is weakest politically. ${ }^{36}$ Local implementation of clean indoor air laws also provides a powerful tool to engage and educate the public during the inevitable battle to get the laws passed. This debate also educates the public about the law and facilitates implementation once the law is passed. ${ }^{37}$

Enacting clean indoor air laws (as well as educational programmes on the health dangers of secondhand smoke) appeal to a broader segment of the population than programmes directed at the smoking minority. Moreover, non-smokers are more open to education on the dangers of passive smoking than smokers are about the dangers of smoking. Non-smokers are also easier to organise for the inevitable political fight because they have something to gain by joining the battle-clean air.

Tobacco industry claims of economic chaos have never been substantiated by objective data. ${ }^{38}$ The greatest threat to clean indoor air policies is enactment of weak state (or federal) laws that pre-empt (take away) the rights of communities to enact local tobacco control legislation. Pre-emption is the tobacco industry's central strategy for fighting clean indoor air laws and should be resisted. ${ }^{39}$

The justification for creation of smoke free workplaces, public places, and homes is protecting non-smokers from the toxins in secondhand smoke, not to impact smoking prevalence. Because it reduces the social acceptability of smoking, however, clean indoor air policies reduce daily cigarette consumption by about $20 \%,{ }^{40}{ }^{41}$ through a combination of reducing smoking prevalence and reducing consumption among continuing smokers. Achieving a reduction in consumption this large would require a tax increase that would double the price of cigarettes.

Clean indoor air is the most cost effective strategy for achieving former US surgeon general C Everett Koop's vision of a smoke free society.

STANTON A GLANTZ

Institute for Health Policy Studies,

Cardiovascular Research Institute, and Department of

Medicine,

University of California,

San Francisco, CA 94143-0130, USA;

glantz@medicine.ucsf.edu

Supported by National Cancer Institute Grant CA-61021.

32 Bal DG, Kizer KW, Felten PG, Mozar HN, Niemeyer D. Reducing tobacco consumption in California: develop-
ment of a statewide anti-tobacco use campaign. $¥ A M A$ 1990;264:1570-4.

33 Pierce JP, Gilpin EA, Emery SL, White M, Rosbrook B, Berry C. Has the California tobacco control program reduced smoking. FAMA 1998;280:893-9 
34 Ong E, Glantz S. Tobacco industry plans to subvert a secondhand smoke study by the International Agency for Research on Cancer. Lancet In press.

35 Glantz S, Charlesworth A. Tourism and hotel revenues before and after passage of smoke free restaurant ordinances. FAMA 1999;281:1911-8.

36 Glantz S, Balbach E. Tobacco war: inside the California battles. Berkeley, California: University of California Press, 2000.

37 Glantz S. Back to basics: Getting smoke free workplaces back on track [editorial]. Tobacco Control 1997;6:164-6.

38 Glantz SA. Smoke free restaurant ordinances don't affect restaurant business. Period. [editorial]. Fournal of Public Health Management \& Practice 1999;5:vi-ix.

39 Siegel M, Carol J, Jordan J, et al. Preemption in tobacco control. Review of an emerging public health problem. FAMA 1997;278:858-63.

40 Chapman S, Borland R, Scollo M, Brownson R, Dominello A, Woodward S. The impact of smoke-free workplaces on A, Woodward S. The impact of smoke-free workplaces on declining cigarette consumption in Australia and
United States. Am 7 Public Health 1999;89:1018-23.

41 Woodruff T, Rosbrook, B, Pierce, J, Glantz, S. Lower levels of cigarette consumption found in smoke free workplaces in California. Arch Intern Med 1993;153:1485-93.

\section{Litigation: USA}

Litigation can accomplish various tobacco control goals. These include:

(1) effectively communicating the dangers of tobacco use through media attention to the plight of individual victims, rather than abstract statistics;

(2) forcing manufacturers to raise prices to cover liability costs, thereby discouraging product use;

(3) delegitimising the tobacco industry by publicising whistleblowers' testimony and their internal incriminating documents, thereby reducing their political power;

(4) compensating individuals, families, and third party payers for their tobacco caused losses;

(5) obtaining judicial orders requiring defendants to change their practices; and

(6) forcing manufacturers, retailers, employers, etc, to "voluntarily" change their practices so as to minimize future compensatory and punitive damages. ${ }^{42}$

Tobacco litigation began in the USA in 1954, and more than 1000 cases have been filed since then. In addition to the "bread and butter" case involving a smoker (or her survivors) suing the manufacturers, the past 10 years have seen non-smokers' lung cancer cases, class actions on behalf of smokers and non-smokers, third party reimbursement cases, and non-smokers' cases against their employers and places of public accommodation. Some cases, most famously the state reimbursement cases, have been settled. A few cases have been won in court, including several awards of punitive damages. Most of the cases have either been voluntarily discontinued, lost (most often at preliminary stages), or are still in the pipeline. Nonetheless, the comparative vastness of the American experience means that best practices for most types of litigation can be found there. ${ }^{43}$

The first goal, communicating dangers, is accomplished even by well publicised losses, of which there have been many. Even if the jury, the media, and the public decide that the smoker should lose because she "knew" the dangers, was "stupid" to keep smoking in the face of them, and hence "deserves" her resulting lung cancer, this in itself is a powerful lesson to smokers and potential smokers. This lesson can be maximised through bringing many individual cases in each country.

The state reimbursement cases demonstrate how the second goal-forcing up prices, decreasing consumption-can be achieved. In the year following the industry's settlement with the 50 states, cigarette prices rose $40 \%$, producing a $10 \%$ drop in consumption. ${ }^{44}$ This benefit can be obtained only by bringing cases in one's own country.

The heroic efforts of attorneys in one state, Minnesota, have realised the third goal through the public release of over 35 million pages of documents, which have already been used in several countries to uncover the industry's machinations and turn the public against them. Lawsuits or official inquiries by governmental bodies outside the US may reveal additional pertinent documents.

Although states have obtained substantial compensation for their tobacco caused medical expenses, most have failed to invest the proceeds in an effective tobacco control programme. While the fourth goal is met through compensation, tobacco control proponents need to participate in the settlement of public cases if the money is to be spent most effectively.

Similarly, while the "master settlement agreement" between 46 states and the industry included judicially enforceable orders ending billboard advertising and some other practices, the fifth goal might have been more comprehensively achieved had tobacco control proponents been involved in the negotiation.

Finally, the relentless pressure of litigation appears to have moved the sixth goal forward, as Philip Morris began in March 2000 to discuss the possibility of submitting itself to regulation. While negotiation is appropriate, the possibility of future litigation should not be abandoned in favour of possibly evanescent industry concessions. ${ }^{45}$

RICHARD A DAYNARD

Northeastern University,

Boston, Massachusetts,

USA;

rdaynard@lynx.neu.edu

42 Daynard RA. Tobacco liability litigation as a cancer control strategy. F Nat Cancer Inst 1988;80:9-11.

43 Daynard RA, Bates C, Francey N. Tobacco litigation worldwide. $B M \mathcal{F} 2000 ; 320: 111-3$.

$44 \mathrm{Hall} \mathrm{K}$. Tobacco likely to hit hard times in 2000. Greensboro News and Record January 16, 2000:5.

45 Bloch M, Daynard RA, Roemer R. A year of living dangerously: the tobacco control community meets the global settlement. Public Health Reports 1998;113:488-97.

\section{Mass media campaigns: Australia, UK, USA}

Over the past few decades, anti-smoking media campaigns have been employed as part of comprehensive tobacco control campaigns in selected US states as well as Australia, UK, Canada, and other countries. It is hard to choose a "best practice" since each campaign has chosen different targets, strategies, and messages. A few outstanding campaigns are highlighted below: 
ADULT CESSATION

Australia: "Every cigarette does you damage"

(see http://www.quitnow.info.aul)

This 1997 campaign provided smokers with new information about the dangers of tobacco use, employed graphic imagery to communicate the dangers, and stressed the immediate harm that tobacco causes. The advertisements were realistic, hard hitting and memorable. They were adapted for use in Massachusetts and pre- and post-surveys found them to be effective in raising the awareness about the dangers of heart disease and stroke and increasing quit attempts and intentions to quits among smokers. They have also been used in Poland, Singapore, and New Zealand.

\section{UK: Fohn Cleese Quitline Advertising}

The UK ran a series of advertisements done by the actor John Cleese that relied on humour to teach quit tips as well as promote the Quitline. The campaign was effective with the calls to Quitline soaring.

PUBLIC OPINION

American Legacy Foundation: "Body bag"

This advertisement featured a group of young people tossing a thousand body bags on the door steps of Philip Morris' New York headquarters. The target was youth, but a greater impact would have been with the general public. Would have been? The advertising was pulled following concerns that it violated the provision of the master settlement agreement which prohibits advertising that vilifies the tobacco industry. The Florida campaign upon which this advertisement was based achieved an impressive decline in youth smoking.

California: "Board room"

This advertisement launched the California campaign and featured a smoke filled room of tobacco executives laughing about how they needed new smokers to replace those that technically died from cancer. A classic that helped push California into the forefront of world tobacco media campaigning.

YOUTH SMOKING

Massachusetts: "Pam"

The "Pam" campaign was a mini-documentary of six, 30 second advertisements about Pam Laffin, a 27 year old who had a lung transplant to treat her emphysema. The campaign dealt with a real person suffering from the horrible consequences of tobacco use. Pam's age was young enough to have youth relate to her condition. The advertising was put into an 18 minute in-school video backed up by a curriculum and seen by thousands of school children throughout the state. A recent study found that the youth exposed to the Massachusetts media campaign were $50 \%$ less likely to smoke than those who were not. ${ }^{46}$

WORST PRACTICE

Philip Morris: youth anti-smoking advertisements This highly stylised $\$ 100$ million PR campaign used a series of advertisements featuring angelic kids telling their more rebellious coun- terparts, “Think. Don't Smoke." Absent were messages about the consequences of smoking. This overly simplistic message could backfire with high risk youths by turning the rotten egg, Marlboro, into forbidden fruit. Mixed messages for youth, but good PR for PM.

GREGORY N CONNOLLY

Massachusetts Tobacco Control Program,

Boston, Massachusetts,

USA;

gregconn@ix.netcom.com

46 Siegel M, Beiner L The impact of an antismoking media campaign on progression to established smoking: results of a longitudinal youth study. Am F Public Health 2000; 90:380-6.

\section{Reducing youth access to tobacco}

The efforts made by the US Food and Drug Administration (FDA) to protect children from tobacco are truly worthy of emulation. In August 1996, the FDA announced that it was asserting jurisdiction over tobacco products. The regulations were comprehensive and included a national prohibition on the sale of tobacco to minors under 18 years of age, a requirement for photographic proof of age for any customer under 27 years of age, a minimum package size of 20 cigarettes, the elimination of all cigarette vending machines accessible to minors, a ban on self service displays, a ban on free sampling, the restriction of advertisements to a black and white "tombstone" format, and the elimination of promotional items. Adverse court rulings have limited the FDA to implementing its restriction only on the sale of tobacco to minors.

In 1997, the FDA contracted with officials in eight states to conduct 5208 compliance checks using underage decoys. During 1998, 28 states conducted 43371 FDA checks, and in 1999, 43 states conducted 93071 checks. The FDA is currently contracted with 53 states and territories to conduct 10000-20000 compliance checks per month. I estimate the number of tobacco retailers in the US to be just over 500000 .

A first offense receives an official warning. This is followed by a civil money penalty of $\$ 250$ for a second offense, $\$ 1500$ for a third, $\$ 5000$ for a fourth, and $\$ 10000$ for a fifth. Retailers who have a first offense will be repeatedly re-inspected until they pass. FDA has sought more than 4300 penalties and retailers have paid over $\$ 750000$ in fines.

Portable computers, the internet, and customised software will soon make it possible for local inspectors to transmit inspection results to the FDA on a daily basis. The results of the first 140000 checks are now available at the FDA's website (www.fda.gov).

I think the FDA's efforts are worthy of recognition for many reasons. First, the regulations are comprehensive and address free sampling, self service, minimum pack size, and vending machines, all of which are important factors in making tobacco available to minors. Second, they recognised that civil prosecution of violators has many advantages over criminal prosecution. Third, they have shown both thoughtfulness and strong initiative in implementing such a complex and 
efficient enforcement programme. Fourth, they have accomplished this in what by bureaucratic standards must be considered lighting speed. Fifth, they have accomplished all of this despite a lack of congressional support in terms of funding and explicit authorisation.

Of course, it just would not do to fail to recognise the pioneering efforts of the community activists in places such as Woodridge, Illinois who established the enforcement programmes and experience upon which the FDA's programme is modelled. States such as Florida and Vermont, which have established statewide enforcement programmes, are also worthy of recognition.

Of great concern is the fates of the FDA regulations and enforcement programme which now rest with the US Supreme Court. If the court finds that Congress did not intend the FDA to have the authority to regulate tobacco, the regulations and enforcement programme will disappear over night. The battle will then move to the Congress as bills will be introduced to establish FDA jurisdiction over tobacco. We will then see how much influence the tobacco industry has bought.

Government regulators in other countries should take a close look at what the US FDA has accomplished.

JOSEPH R DIFRANZA

Department of Family Medicine and Community Health, University of Massachusetts Medical School,

55 Lake Avenue, Worcester,

Massachusetts 01655, USA;

joe.difranza@banyan.ummed.edu 